\title{
LINFONODOS CALCIFICADOS: UM ACHADO RADIOGRÁFICO IMPORTANTE
}

Thaís Santiago GOULARTE, Ângela FERNANDES, Fernando Henrique WESTPHALEN, Antonio Adilson Soares DE LIMA, Anna Silvia Setti DA ROSA

As calcificações de tecido mole são comuns, estando presentes em cerca de 4\% das radiografias panorâmicas (WHITE \& PHAROAH, 2007). A calcificação dos linfonodos é uma dessas condições e pode ter várias causas: tuberculose, vacina BCG, sarcoidose, doença da arranhadura do gato, infecções fúngicas, linfomas submetidos à radioterapia prévia e metástases de neoplasias calcificantes distantes. A calcificação de linfonodos geralmente é assintomática e encontrada ao acaso em radiografias panorâmicas. Os linfonodos comumente envolvidos são os submandibulares e cervicais. A maioria não necessita tratamento, porém é importante determinar a causa, pois o tratamento poderá ser necessário (LANGLAIS et al. 1995; WOOD \& GOAZ, 2004). Este trabalho relata um caso de linfonodos calcificados cervicais, assintomáticos, observados na radiografia panorâmica de paciente feminino, com 38 anos de idade. Foram realizados exames complementares, incluindo tomografia computadorizada volumétrica para confirmar a hipótese diagnóstica. É importante que o profissional esteja atento aos diferentes tipos de calcificações em tecidos moles que podem ser observados na panorâmica para saber diferenciá-los e determinar a necessidade de tratamento ou outros métodos de investigação. É fundamental orientar adequadamente o paciente e, quando necessário, encaminhá-lo a um serviço médico como nos casos de ateromas em artéria carótida.

Palavras-chave: linfonodos calcificados; radiografia panorâmica; calcificações em tecidos moles. 